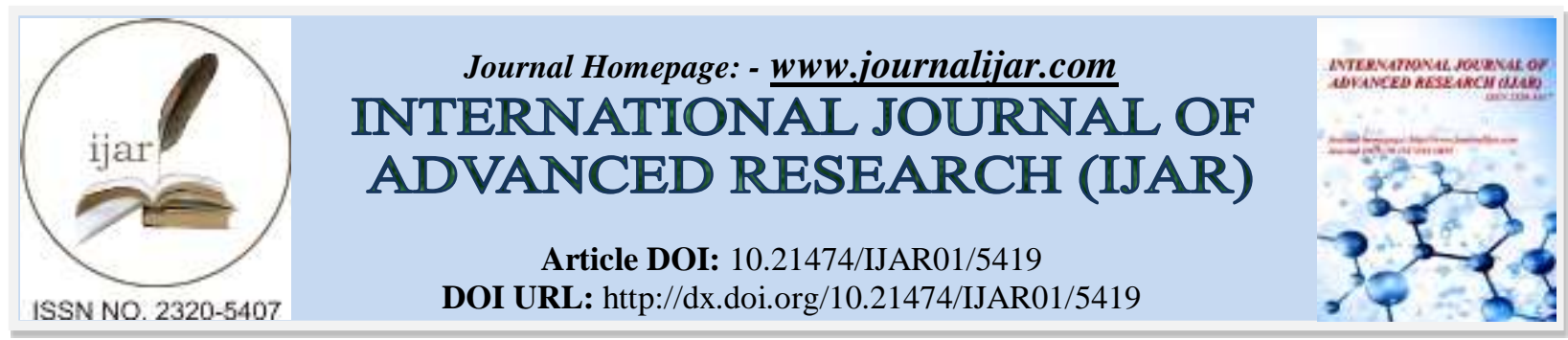

RESEARCH ARTICLE

\title{
CLINICOPATHOLOGICAL SIGNIFICANCE OF FASCIN1 AND B-CATENIN EXPRESSION IN COLORECTAL ADENOCARCINOMA; AN IMMUNOHISTOCHEMICAL STUDY"
}

\author{
Hanaa A. Atwa ${ }^{1}$, Abeer M. AbdElbary ${ }^{1}$, Taha A Baiomy ${ }^{2}$ and Yasser A. Orban ${ }^{2}$. \\ 1. Pathology Department, Faculty of medicine, Zagazig University, Egypt. \\ 2. General surgery Department, Faculty of medicine, Zagazig University, Egypt.
}

\section{Manuscript Info}

Manuscript History

Received: 13 July 2017

Final Accepted: 15 August 2017

Published: September 2017

Key words:-

Fascin $1 \& \beta$-catenin; colorectal

adenocarcinoma;

Immunohistochemistry; prognosis.

\section{Abstract}

Background: Colorectal cancer (CRC) is the fourth most common human malignancies worldwide. Fascin1 is an actin bundling protein along the entire length of filopodia and its diminution leads to reduction in the number of filopodia. Beta-catenin ( $\beta$-catenin) is one of the catenin protein family, involved in the regulation of adhesion between the cells and gene transcription. It is one of the cadherin protein complexes acting as intracellular signal transducer in the Wnt signaling pathway.

Objective: we aimed in this study to investigate the immunohistochemical expression of FascinI and $\boldsymbol{\beta}$ - catenine incancer colon and correlate their expression with other clinicopathologic features.

Material and methods: 45cases of colorectal adenocarcinoma and 30 cases of adenomatous polyp were collected from Pathology Department. Faculty of Medicine. Zagazig University between January 2013 to December 2016, using immunohistochemical antibodies to Fascin 1 and $\beta$ - catenine.

Results: positive Fascin1 expression was observed in 31.1\%) and $40 \%$ of CRC and colorectal adenomatous polyp respectively. Positive $\boldsymbol{\beta}$ catenineimmunohistochemicalstaining (IHC) where $35.6 \%$ and $40 \%$ $\mathrm{CRC}$ and colorectal adenomatous polyp.

The expression of cytoplasmic $\boldsymbol{\beta}$ - catenin protein in CRCwas significantly $(\mathrm{p}=0.0001)$ higher than in the adenomatous polyp.

Both markers are significantly correlated with tumor grade $(\mathrm{p}<<0.001)$. No significant association between (IHC) staining was found between both markers expression and $\mathrm{N}$ stage of tumor. Expressions of both of them were significantly positively correlated with each other $(\mathrm{p}<0.001)$. Conclusion: Fascin 1 has known roles in cell morphology and migration and may represent a potential novel marker or therapeutic target for patients with colorectal cancer.Fascin 1 is regulated by $\boldsymbol{\beta}$ catenine. IHC staining of $\beta$-catenin is considered a useful marker to predict the prognosis in colorectal cancer (CRC). Keywords: Fascin1; Bcatenin; colorectal cancer; immunohistochemistry; prognosis

Copy Right, IJAR, 2017,. All rights reserved. 


\section{Introduction:-}

Colorectal cancer (CRC) is the fourth most common human malignancies worldwide[1].CRC remains the second main cause of cancer related mortality. The 5-year survival rate for CRC exceeds $50 \%$ depends on the stage of the disease[2]. Recently molecular markers are considered essential factors that affect CRC patient prognosis.Fascin1 is an actin bundling protein along the entire length of filopodia and its diminution leads to reduction in the number of filopodia[7]. Fascin 1 promotes cell migration, neuronal tissue normally express the Fascin 1 and is not expressed in normal epithelial cell. Invasion of cancer cells occurs through presence of sensory organelles called filopodia hustling of actin filaments. Many researches noticed that Fascin 1 significantly accelerate cell migration in transfilter assays $[8,9]$. Fascin1 expression was recognized in many types of malignant cells, including colonic carcinoma $[8,10,11]$.

Beta-catenin ( $\beta$-catenin) is one of the catenin protein families, involved in the regulation of adhesion between the cells and gene transcription. It is one of the cadherin protein complex acting as intracellular signal transducer in the Wnt signaling pathway [3]. Different type of malignancy can affect by the degree of $\beta$-catenin expression and the rearrangement of its genes [4].B-catenin expression in CRC outcome is tarnished. The prognostic importance of different forms of $\beta$-catenin expression either cytoplasmic, or nuclear accumulation of it may be an autonomous marker of poor prediction $[\mathbf{5 , 6}]$.

So we aimed in this study to investigate the expression of Fascin 1 and $\beta$ - catenine in colorectal carcinoma and their correlation with other clinicopathological features.

\section{Material and Methods:-}

This is a prospective cohort study, where 75 cases of colorectal masses were admitted to general surgery hospital oncology unit, faculty of medicine Zagazig University, in the period between January 2013 to December 2016. 45 cases of them that were diagnosed as colorectal adenocarcinoma and were managed by right hemicolectomy, left hemicolectomy, transverse colectomy sigmoidectomy and proctocolectomy with radical excision of the mesocolon and mesorectum, 30 cases of them were diagnosed as adenomatous polyp and excisional biopsy was done to all cases. Samples of all cases were sent to Pathology Department. Faculty of Medicine Zagazig University where they were processed and subjected to routine hematoxylin and eosin staining, diagnosed and carcinoma cases were graded and staged.

In patients submitted to surgery for CRC, tissue samples were obtained from the tumor and from adjacent nonneoplastic colorectal mucosa.

\section{Immunohistochemical staining:-}

We used streptavidine-biotin technique [12].Paraffin-embedded blocks have been cut in to Four-micron thick sections, deparaffinisation was done in series of xylene and rehydratation was done in descending grades of alcohol, for blooking endogenous peroxidase activity the section were placed in $0.5 \%$ hydrogen peroxide in methanol for 10 min microwave antigen retrieval.

Primary mouse monoclonal antibody directed against Fascin1 (DakoCytomation, Carpenteria, CA, USA used at a 1:50dilution) and rabbit polyclonal primary anti- $\beta$ - -catenin antibody (Santa Cruz Biotechnology, Inc.,Santa Cruz, CA, USA used at dilution1:100) and by employing diaminobenzidine (DAB) as the chromogen. Were added for 30 minutes at room temperature. Secondary antibody was addedto sections for 30 minutes. After incubation, the reaction product was seenby diaminobenzidine. At the end, the sections were counterstained with Mayer's hematoxylin. Negative controls had primary antibody replaced by buffer.

\section{Immunohistochemical evaluation of both markers:- For Fascin1 expression}

Fascin 1-positive cells were graded as follows: <5percentage, 0; 5-25\%, 1+;25-75\%, 2+; and >75\%, 3+. Staining of $>5 \%$ of cancer cells was recorded as positive immunoreactivity) [13].

\section{For $\beta$ - catenine expression}

$\beta$ - catenine positive expression it was graded using a range of $0-3$ as follows: 0 , No staining; 1 , weak staining; 2 , moderate staining; and 3, strong staining. [14].Membrane staining, four categories were used $(+++,++,+,-[15]$.The 
cytoplasmic staining was also graded into 4categories: (0) Negative, no detectable staining, (1) Weak, (2) Moderae, (3) intense staining, intense. The nuclear staining index (NI) was also graded to into four categories $(+++,++,+,-)$ : all forms of expression ranged from (0) Negative (1) Weak (2) Moderate (3) Heavy staining. The extent of staining was graded on a scale as follows: $0, \leq 5 \% ; 1,6-25 \% ; 2,26-50 \% ; 3,51-75 \%$; or $4,76-100 \%$ according to the percentage of the section that has positive staining. The intensity and extent scores were multiplied to generate the immunoreactivity score (IS; range, 0-12) for each case[16]. High cytoplasmic and nuclear $\beta$-catenin expression grades were defined as $>50 \%$ reactivity of the tumor cells [17].

\section{Statistical Analysis:-}

Continuous variables were expressed as the mean \pm SD \& median (range), and the categorical variables were expressed as a number(percentage). Continuous variables were checked for normality by using Shapiro-Wilk test. Independent samples Student's t-test was used to compare between two groups of normally distributed variables while Mann Whitney U test was used for non-normally distributed variables. Percent of categorical variables were compared using the Pearson's Chi-square test or Fisher's exact test when was appropriate. Trend of change in distribution of relative frequencies between ordinal data were compared using Chi-square test for trend. Correlation between immunohistochemical markers was analyzed usingSperman correlation. A p-value $<0.05$ was considered significant. All statistics were performed using SPSS.

\section{Results:-}

\section{Clinico-pathological results:-}

For patients operated with CRC, 25 were females and 20 were males. The median age was 55(43-80) years and $60 \%$ of the CRC was in the colon in while $40 \%$ of cases wasin the rectum.

Regarding adenomatous polyp, 15 patients were male and 15 were female. The median age was $60.7 \pm 3.4$ years $(29$ to 88 years). $46.7 \%$ of polyp present in the left colon and $43.3 \%$ in the right colon. table 1

\section{Immunohistochemical results (table 2,3 and 4):-}

Fascin1 was stained in the cytoplasm of cancer cells (Figure 1,2,3,4and 5). B- catenine expression may be membrance, cytoplasmic or nuclear. Figure 6,7,8,9,10,11and12).

In this study,Fascin1 was negative in normal mucosa but only detected in infiltrating stromal cells, in the extracellular matrix, fibroblasts and blood vessel. $\beta$-catenin staining was commonlyseen at cell-cell junction sitesin normal colon epithelium, whereas. In the more differentiated adenocarcinoma, $\beta$-catenin staining was observedin the membrane and in the cytoplasm with weak or no nuclear staining. On the contrary, the invasive front of tumors exhibiting cytoplasmic and nuclear $\beta$-catenin localization. Fascin 1 expression was high in sheets of invading tumor cells.

- Positive Fascin 1 expression was observed in 31.1\%and 40\% of colorectal cancer and colorectal adenomatous polyp respectively. Positive $\beta$ - catenineIHC staining where $35.6 \%$ and $40 \%$ colorectal cancer and colorectal adenomatous polyp.

- Positive Fascin 1 expression is significantly correlated with L.N state $(\mathrm{p}=0.0497)$

- $\quad$ Both markers are significantly correlated with tumor grade $(\mathrm{p}<0.001)$.

- There is statistically significant difference between cytoplasmic beta-catenin expression andadenomatous polyp $(\mathrm{p}=0.0001)$.

- No significant association between IHC staining of both markers andstage of tumor.

- Expressions of both markers were significantly positively correlated with each other $(\mathrm{p}=0.0001)$

Table (1):- Comparison between colorectal cancer group and polyp group.

\begin{tabular}{|c|c|c|c|c|c|}
\hline & \multicolumn{2}{|c|}{$\begin{array}{l}\text { Caner group } \\
(\mathrm{N}=45)\end{array}$} & \multicolumn{2}{|c|}{$\begin{array}{l}\text { Adenomatous } \\
\text { group } \\
(\mathrm{N}=30)\end{array}$} & \multirow[t]{2}{*}{ p-value } \\
\hline & No. & $(\%)$ & No. & $(\%)$ & \\
\hline \multicolumn{6}{|l|}{ Age (years) } \\
\hline Mean \pm SD & 57.33 & \pm 8.78 & 58.78 & \pm 4.32 & \multirow[t]{2}{*}{$0.312 \bullet$} \\
\hline Median (Range) & 55 & $(43-80)$ & 60 & $(47-66)$ & \\
\hline
\end{tabular}




\begin{tabular}{|c|c|c|c|c|c|}
\hline $36-45$ years & $\beta$ & $(6.7 \%)$ & 0 & $(0 \%)$ & \multirow[t]{3}{*}{0.2931} \\
\hline $46-60$ years & 28 & $(62.2 \%)$ & & $22(73.3 \%)$ & \\
\hline$>60$ years & 14 & $(31.1 \%)$ & 8 & $(26.6 \%)$ & \\
\hline \multicolumn{6}{|l|}{ Sex } \\
\hline Male & 20 & $(44.4 \%)$ & 15 & $(50 \%)$ & \multirow[t]{2}{*}{0.6366} \\
\hline Female & 25 & $(55.6 \%)$ & 15 & $(50 \%)$ & \\
\hline \multicolumn{6}{|l|}{ Location } \\
\hline Rt colon & 14 & $(31.1 \%)$ & 13 & $(43.3 \%)$ & \multirow[t]{4}{*}{0.0018} \\
\hline Transverse colon & 5 & $(11.1 \%)$ & 0 & $(0 \%)$ & \\
\hline Lt colon & 8 & $(17.8 \%)$ & 14 & $(46.7 \%)$ & \\
\hline Rectum & 18 & $(40 \%)$ & 3 & $(10 \%)$ & \\
\hline \multicolumn{6}{|l|}{ Number } \\
\hline Single & 39 & $(86.7 \%)$ & 27 & $(90 \%)$ & \multirow[t]{2}{*}{0.6634} \\
\hline Multiple & 6 & $(13.3 \%)$ & 3 & $(10 \%)$ & \\
\hline \multicolumn{6}{|l|}{ Size $(\mathrm{cm})$} \\
\hline Mean \pm SD & 74.17 & \pm 18.52 & 8.78 & \pm 6.30 & \multirow[t]{2}{*}{$<0.001^{\bullet}$} \\
\hline Median (Range) & 75 & $(30-120)$ & 7 & $(4-40)$ & \\
\hline$<10 \mathrm{~mm}$ & 0 & $(0 \%)$ & 22 & $(73.3 \%)$ & \multirow[t]{3}{*}{$<0.001$} \\
\hline $10-50 \mathrm{~mm}$ & 6 & $(13.3 \%)$ & 8 & $(26.7 \%)$ & \\
\hline$>50 \mathrm{~mm}$ & 39 & $(86.7 \%)$ & 0 & $(0 \%)$ & \\
\hline \multicolumn{6}{|l|}{ Histopathological type } \\
\hline Tubular adenoma & p & $(0 \%)$ & 10 & $(33.3 \%)$ & \multirow[t]{4}{*}{$<0.001$} \\
\hline Tubullovillous adenoma & p & $(0 \%)$ & 18 & $(60 \%)$ & \\
\hline Villous adenoma & p & $(0 \%)$ & 2 & $(6.66 \%)$ & \\
\hline Adenocarcinoma & 45 & $(100 \%)$ & 0 & $(0 \%)$ & \\
\hline \multicolumn{6}{|l|}{ Grade } \\
\hline Low grade dysplasia & p & $(0 \%)$ & 26 & $(86.7 \%)$ & \multirow[t]{5}{*}{$<0.001$} \\
\hline High grade dysplasia & p & $(0 \%)$ & 4 & $(13.3 \%)$ & \\
\hline Grade 1 & 31 & $(68.9 \%)$ & 0 & $(0 \%)$ & \\
\hline Grade 2 & 9 & $(20 \%)$ & 0 & $(0 \%)$ & \\
\hline Grade 3 & 5 & $(11.1 \%)$ & 0 & $(0 \%)$ & \\
\hline \multicolumn{6}{|l|}{ Cytoplasmic Fascin1 } \\
\hline Negative & 31 & $(68.8 \%)$ & 18 & $(60 \%)$ & \multirow[t]{2}{*}{0.4281} \\
\hline Positive & 14 & $(31.1 \%)$ & 12 & $(40 \%)$ & \\
\hline \multicolumn{6}{|l|}{$\beta$ - catenin } \\
\hline Negative & 29 & $(64.4 \%)$ & 18 & $(60 \%)$ & \multirow[t]{2}{*}{0.6967} \\
\hline Positive & 16 & $(35.6 \%)$ & 12 & $(40 \%)$ & \\
\hline \multicolumn{6}{|l|}{ Nuclear $\beta$ - catenin } \\
\hline Positive & 22 & $(48.9 \%)$ & 11 & $(36.66 \%)$ & \\
\hline Negative & 23 & $(51.1 \%)$ & 19 & $(63.33 \%)$ & 0.2962 \\
\hline \multicolumn{6}{|l|}{ Cytoplasmic $\beta$ - catenin } \\
\hline Positive & 12 & $(26.7 \%)$ & 22 & $(73.3 \%)$ & \multirow[t]{2}{*}{0.0001} \\
\hline Negative & 33 & $(73.3 \%)$ & 8 & $(26.7 \%)$ & \\
\hline \multicolumn{6}{|l|}{ Membranous $\beta$ - catenin } \\
\hline Positive & 12 & $(26.7 \%)$ & 11 & $(36.7 \%)$ & \multirow[t]{2}{*}{0.3575} \\
\hline Negative & 33 & $(73.3 \%)$ & 19 & $(63.3 . \%)$ & \\
\hline
\end{tabular}

Categorical variables were expressed as number(percentage).

Continuous variables were expressed as mean \pm SD \& median (range).

- Mann Whitney U test;§Chi-square test.

$\mathrm{p}<0.05$ is significant. 
Table (2):- Relation between clinicopathological featuresand immunohistochemicalmarkers in 45 patients with colorectal carcinoma.

\begin{tabular}{|c|c|c|c|c|c|c|c|c|c|c|c|c|}
\hline \multirow{3}{*}{$\begin{array}{l}\text { Characteristic } \\
\mathrm{s}\end{array}$} & \multirow{2}{*}{\multicolumn{2}{|c|}{ All }} & \multicolumn{4}{|c|}{ Cytoplasmic Fascin 1} & \multirow{3}{*}{$\begin{array}{c}\text { p- } \\
\text { valu } \\
\mathrm{e}\end{array}$} & \multicolumn{4}{|c|}{$\beta$ - catenin } & \multirow{3}{*}{$\begin{array}{l}\mathrm{p}- \\
\text { value }\end{array}$} \\
\hline & & & \multicolumn{2}{|c|}{$\begin{array}{l}\text { Negative } \\
(\mathrm{N}=31)\end{array}$} & \multicolumn{2}{|c|}{$\begin{array}{l}\text { Positive } \\
(\mathrm{N}=14)\end{array}$} & & \multicolumn{2}{|c|}{$\begin{array}{c}\text { Negative } \\
(\mathrm{N}=29)\end{array}$} & \multicolumn{2}{|c|}{$\begin{array}{c}\text { Positive } \\
(\mathrm{N}=16)\end{array}$} & \\
\hline & No. & $(\%)$ & No. & $(\%)$ & No. & $(\%)$ & & No. & $(\%)$ & No. & $(\%)$ & \\
\hline \multicolumn{13}{|l|}{ Age (years) } \\
\hline Mean \pm SD & $\begin{array}{c}57.3 \\
3\end{array}$ & \pm 8.78 & $\begin{array}{c}55.8 \\
1\end{array}$ & \pm 7.71 & $\begin{array}{c}58.7 \\
8\end{array}$ & \pm 9.63 & \multirow[t]{2}{*}{$0.262 *$} & $\begin{array}{c}54.3 \\
6\end{array}$ & \pm 5.44 & $\begin{array}{c}58.2 \\
9\end{array}$ & \pm 9.48 & \multirow[t]{2}{*}{$\begin{array}{l}0.099 \\
*\end{array}$} \\
\hline $\begin{array}{l}\text { Median } \\
\text { (Range) }\end{array}$ & 55 & $(43-80)$ & $\begin{array}{c}54.5 \\
0\end{array}$ & $(44-76)$ & 60 & $(43-80)$ & & 53 & $(45-62)$ & $\begin{array}{c}55.5 \\
0\end{array}$ & $(43-80)$ & \\
\hline $36-45$ years & 3 & $(6.7 \%)$ & 1 & $(3.22 \%)$ & 2 & $\begin{array}{c}(14.2 \% \\
)\end{array}$ & \multirow[t]{3}{*}{$<0.001$} & 2 & $(6.89 \%)$ & 1 & $(6.25 \%)$ & \multirow[t]{3}{*}{.9965} \\
\hline $46-60$ years & 28 & $\begin{array}{c}62.2 \% \\
)\end{array}$ & 26 & $(83.8 \%)$ & 2 & $\begin{array}{c}(14.2 \% \\
)\end{array}$ & & 18 & $(62.1 \%)$ & 10 & $(62.5 \%)$ & \\
\hline$>60$ years & 14 & $\begin{array}{c}(31.1 \% \\
)\end{array}$ & 4 & $(21.9 \%)$ & 10 & $\begin{array}{c}(42.9 \% \\
)\end{array}$ & & 9 & $(31.1 \%)$ & 5 & $(31.3 \%)$ & \\
\hline \multicolumn{13}{|l|}{ Sex } \\
\hline Male & 20 & $\begin{array}{c}(44.4 \% \\
)\end{array}$ & 12 & $(38.7 \%)$ & 8 & $\begin{array}{c}(57.2 \% \\
)\end{array}$ & \multirow[t]{2}{*}{0.2493} & 10 & $(34.4 \%)$ & 10 & $(62.5 \%)$ & \multirow[t]{2}{*}{$\begin{array}{l}0.070 \\
2\end{array}$} \\
\hline Female & 25 & $\begin{array}{c}55.6 \% \\
)\end{array}$ & 19 & $(61.3 \%)$ & 6 & $\begin{array}{c}(42.8 \% \\
)\end{array}$ & & 19 & $(65.5 \%)$ & 6 & $(37.5 \%)$ & \\
\hline \multicolumn{13}{|l|}{ Location } \\
\hline Rt colon & 14 & $\begin{array}{c}(31.1 \% \\
)\end{array}$ & 10 & $(32.2 \%)$ & 4 & $\begin{array}{c}(28.5 \% \\
)\end{array}$ & \multirow[t]{4}{*}{0.1082} & 8 & $(27.5 \%)$ & 6 & $(37.5 \%)$ & \multirow[t]{4}{*}{$\begin{array}{l}0.058 \\
8\end{array}$} \\
\hline $\begin{array}{l}\text { Transverse } \\
\text { colon }\end{array}$ & 5 & $\begin{array}{c}(11.1 \% \\
)\end{array}$ & 5 & $\begin{array}{c}(16.1 . \% \\
)\end{array}$ & 0 & $(0 \%)$ & & 1 & $(3.22 \%)$ & 4 & $(25 \%)$ & \\
\hline Lt colon & 8 & $\begin{array}{c}(17.8 \% \\
)\end{array}$ & 3 & $(9.67 \%)$ & 5 & $\begin{array}{c}(35.7 \% \\
)\end{array}$ & & 5 & $(17.2 \%)$ & 3 & $\begin{array}{c}(18.75 \% \\
)\end{array}$ & \\
\hline Rectum & 18 & $(40 \%)$ & 13 & $(41.9 \%)$ & 5 & $\begin{array}{c}(35.7 \% \\
)\end{array}$ & & 15 & $(51.7 \%)$ & 3 & $\begin{array}{c}(18.75 \% \\
)\end{array}$ & \\
\hline \multicolumn{13}{|l|}{ Number } \\
\hline Single & 39 & $\begin{array}{c}86.7 \% \\
)\end{array}$ & 29 & $(93.5 \%)$ & 10 & $\begin{array}{c}(42.9 \% \\
)\end{array}$ & \multirow[t]{2}{*}{0.0433} & 28 & $(96.6 \%)$ & 11 & $(68.7 \%)$ & \multirow[t]{2}{*}{$\begin{array}{l}0.008 \\
6\end{array}$} \\
\hline Multiple & 6 & $\begin{array}{c}13.3 \% \\
)\end{array}$ & 2 & $(6.45 \%)$ & 4 & $\begin{array}{c}(28.5 \% \\
)\end{array}$ & & 1 & $(3.22 \%)$ & 5 & $(31.3 \%)$ & \\
\hline \multicolumn{13}{|l|}{ Gross pattern } \\
\hline Ulcerative & 23 & $(50 \%)$ & 14 & $(45.1 \%)$ & 9 & $\begin{array}{c}(64.3 \% \\
)\end{array}$ & \multirow[t]{3}{*}{0.3310} & 17 & $(58.6 \%)$ & 6 & $(37.5 \%)$ & $\begin{array}{l}0.020 \\
9\end{array}$ \\
\hline Fungating & 9 & $\begin{array}{c}20.5 \% \\
)\end{array}$ & 6 & $(19.3 \%)$ & 3 & $\begin{array}{c}(21.4 \% \\
)\end{array}$ & & & $\begin{array}{c}7(24.1 \% \\
)\end{array}$ & 2 & $(12.5 \%)$ & \\
\hline Annular & 13 & $\begin{array}{c}29.5 \% \\
)\end{array}$ & 11 & $(35.4 \%)$ & 2 & $\begin{array}{c}(14.2 \% \\
)\end{array}$ & & 4 & $(13.7 \%)$ & 9 & $\left(\begin{array}{c}56.25 \% \\
)\end{array}\right.$ & \\
\hline Size $(\mathrm{cm})$ & & & & & & & & & & & & \\
\hline Mean \pm SD & $\begin{array}{c}74.1 \\
7\end{array}$ & \pm 18.52 & $\begin{array}{c}74.9 \\
0\end{array}$ & \pm 19.15 & $\begin{array}{c}73.4 \\
7\end{array}$ & \pm 18.30 & $0.799 *$ & 75 & \pm 22.47 & $\begin{array}{c}73.9 \\
1\end{array}$ & \pm 17.44 & $\begin{array}{l}0.868 \\
*\end{array}$ \\
\hline $\begin{array}{l}\text { Median } \\
\text { (Range) }\end{array}$ & 75 & $\begin{array}{l}(30- \\
120)\end{array}$ & 75 & $\begin{array}{l}(40- \\
120)\end{array}$ & 75 & $\begin{array}{l}(30- \\
100)\end{array}$ & & 70 & $(40-120)$ & $\begin{array}{c}77.5 \\
0\end{array}$ & $(30-100)$ & \\
\hline $10-50 \mathrm{~mm}$ & 7 & $\begin{array}{c}(13.3 \% \\
)\end{array}$ & 5 & $(16.1 \%)$ & 2 & $\begin{array}{c}(14.2 \% \\
)\end{array}$ & 0.8745 & 3 & $(10.3 \%)$ & 4 & $(25 \%)$ & $\begin{array}{l}0.194 \\
1\end{array}$ \\
\hline$>50 \mathrm{~mm}$ & 38 & $\begin{array}{c}86.7 \% \\
)\end{array}$ & 26 & $(83.8 \%)$ & 12 & $\begin{array}{c}85.7 \% \\
)\end{array}$ & & 26 & $(89.6 \%)$ & 12 & $(75 \%)$ & \\
\hline Grade & & & & & & & & & & & & \\
\hline Grade 1 & 27 & $68.9 \%$ & 25 & $(80.6 \%)$ & 2 & $(14.3 \%$ & 0.0001 & 26 & $(89.6 \%)$ & 1 & $(6.25 \%)$ & $<0.00$ \\
\hline
\end{tabular}




\begin{tabular}{|c|c|c|c|c|c|c|c|c|c|c|c|c|}
\hline & & ) & & & & ) & & & & & & \multirow[t]{3}{*}{1} \\
\hline Grade 2 & 9 & $(20 \%)$ & 4 & $(12.8 \%)$ & 5 & $\begin{array}{c}(35.7 \% \\
)\end{array}$ & & 1 & $(3.22 \%)$ & 8 & $(50 \%)$ & \\
\hline Grade 3 & 9 & $\begin{array}{c}(11.1 \% \\
)\end{array}$ & 2 & $(6.45 \%)$ & 7 & $(50 \%)$ & & 2 & $(6.89 \%)$ & 7 & $\begin{array}{c}(43.75 \% \\
)\end{array}$ & \\
\hline \multirow{2}{*}{\multicolumn{12}{|c|}{$\mathrm{T}$}} & \\
\hline & & & & & & & & & & & & \\
\hline $\mathrm{T} 1$ & 2 & $(4.4 \%)$ & 1 & $(3.22 \%)$ & 1 & $\begin{array}{c}(7.14 \% \\
)\end{array}$ & \multirow[t]{3}{*}{0.3095} & 1 & $(3.22 \%)$ & 1 & $(6.25 \%)$ & \multirow[t]{3}{*}{\begin{tabular}{|l}
0.446 \\
6
\end{tabular}} \\
\hline $\mathrm{T} 2$ & 3 & $(6.7 \%)$ & 1 & $(3.22 \%)$ & 2 & $\begin{array}{c}(14.2 \% \\
)\end{array}$ & & 1 & $(3.22 \%)$ & 2 & $(12.5 \%)$ & \\
\hline T3 & 40 & $\begin{array}{c}(88.9 \% \\
)\end{array}$ & 29 & $(93.5 \%)$ & 11 & $\begin{array}{c}(78.5 \% \\
)\end{array}$ & & 27 & $(93.1 \%)$ & 13 & $\begin{array}{c}(81.25 \% \\
)\end{array}$ & \\
\hline \multicolumn{13}{|l|}{$\mathrm{N}$} \\
\hline N0 & 11 & $\begin{array}{c}(24.4 \% \\
)\end{array}$ & 10 & $(91 \%)$ & 1 & $(10 \%)$ & \multirow[t]{2}{*}{0.0497} & 9 & $(81.8 \%)$ & 2 & $(18.2 \%)$ & \multirow[t]{2}{*}{$\begin{array}{l}0.286 \\
6\end{array}$} \\
\hline N1 & 34 & $\begin{array}{c}(75.6 \% \\
)\end{array}$ & 20 & $|(58.8 \%)|$ & 14 & $\begin{array}{c}(41.2 \% \\
)\end{array}$ & & 22 & $\mid(64.7 \%)$ & 12 & $35.3 \%)$ & \\
\hline \multicolumn{13}{|l|}{ Stage } \\
\hline Stage I & 2 & $(4.4 \%)$ & 1 & $(3.22 \%)$ & 1 & $\begin{array}{c}(7.14 \% \\
)\end{array}$ & \multirow[t]{3}{*}{0.3095} & 1 & $(3.22 \%) \mid$ & 1 & $(6.25 \%)$ & \multirow[t]{3}{*}{$\begin{array}{l}0.907 \\
6\end{array}$} \\
\hline Stage II & 3 & $(6.7 \%)$ & 1 & $(3.22 \%)$ & 2 & $\begin{array}{c}(14.2 \% \\
)\end{array}$ & & 2 & $(6.89 \%)$ & 1 & $(6.25)$ & \\
\hline Stage III & 40 & $\begin{array}{c}(88.9 \% \\
)\end{array}$ & 29 & $(93.5 \%)$ & 11 & $\begin{array}{c}(78.5 \% \\
)\end{array}$ & & 26 & $(89.6 \%) \mid$ & 14 & $(87.5 \%)$ & \\
\hline \multicolumn{13}{|c|}{$\begin{array}{l}\text { Cytoplasmic } \\
\text { Fascin1 }\end{array}$} \\
\hline Negative & 31 & $\begin{array}{c}68.8 \% \\
)\end{array}$ & & & & & & 26 & $(89.6 \%)$ & 5 & $(31 \%)$ & \multirow[t]{2}{*}{\begin{tabular}{|l|}
0.000 \\
1
\end{tabular}} \\
\hline Positive & 14 & $\begin{array}{c}(31.1 \% \\
)\end{array}$ & & & & & & 3 & $(10.3 \%)$ & 11 & $(68.1 \%)$ & \\
\hline \multicolumn{13}{|l|}{$\beta$ - catenin } \\
\hline Negative & 29 & $\begin{array}{c}(64.4 \% \\
)\end{array}$ & 26 & $(89.6 \%)$ & 3 & $\begin{array}{c}(10.3 \% \\
)\end{array}$ & \multirow[t]{2}{*}{0.0001} & & & & & \\
\hline Positive & 16 & $(35.6 \%)$ & 5 & $(31.3 \%)$ & 11 & $\begin{array}{c}(68.1 \% \\
)\end{array}$ & & & & & & \\
\hline
\end{tabular}

- Categorical variables were expressed as number(percentage), continuous variables were expressed as mean \pm SD \& median (range).

- * Independent samples Student's t-test;§Chi-square test; $\$$ Chi-square test for trend; $p<0.05$ is significant.

Table (3):- Relation between clinicopathologicalfeaturesandimmunohistochemical markers in 45 patients with colorectal carcinoma.

\begin{tabular}{|c|c|c|c|c|c|c|c|c|c|c|c|c|c|c|c|c|c|}
\hline \multirow[t]{3}{*}{$\begin{array}{c}\text { Characteris } \\
\text { tics }\end{array}$} & \multirow{2}{*}{\multicolumn{2}{|c|}{$\begin{array}{c}\text { All } \\
(\mathrm{N}=45 \\
)\end{array}$}} & \multicolumn{4}{|c|}{ Nuclear $\beta$ catenin } & \multirow[t]{3}{*}{$\begin{array}{c}\mathrm{p}- \\
\text { value }\end{array}$} & \multicolumn{4}{|c|}{$\begin{array}{c}\text { Cytoplasmic } \beta- \\
\text { catenin }\end{array}$} & \multirow[t]{3}{*}{$\begin{array}{c}\mathrm{p}- \\
\text { value }\end{array}$} & \multicolumn{4}{|c|}{$\begin{array}{c}\text { Membranous } \beta \\
\text { catenin }\end{array}$} & \multirow[t]{3}{*}{$\begin{array}{c}\mathrm{p}- \\
\text { value }\end{array}$} \\
\hline & & & \multicolumn{2}{|c|}{$\begin{array}{c}\text { Negati } \\
\text { ve } \\
(\mathrm{N}=23 \\
)\end{array}$} & \multicolumn{2}{|c|}{$\begin{array}{c}\text { Positiv } \\
\mathrm{e} \\
(\mathrm{N}=22 \\
)\end{array}$} & & \multicolumn{2}{|c|}{$\begin{array}{c}\text { positiv } \\
\mathrm{e} \\
(\mathrm{N}=12 \\
)\end{array}$} & \multicolumn{2}{|c|}{$\begin{array}{c}\text { negati } \\
\text { ve } \\
(\mathrm{N}=33 \\
)\end{array}$} & & \multicolumn{2}{|c|}{$\begin{array}{c}\text { positiv } \\
\mathrm{e} \\
(\mathrm{N}=12 \\
)\end{array}$} & \multicolumn{2}{|c|}{$\begin{array}{c}\text { negati } \\
\text { ve } \\
(\mathrm{N}=33 \\
)\end{array}$} & \\
\hline & No. & $(\%)$ & No & $(\%)$ & No. & $(\%)$ & & No. & $(\%)$ & No. & $(\%)$ & & No. & $(\%)$ & No. & $(\%)$ & \\
\hline $\begin{array}{c}\text { Age } \\
\text { (years) }\end{array}$ & & & & & & & & & & & & & & & & & \\
\hline $\begin{array}{l}\text { Mean } \pm \\
\text { SD }\end{array}$ & $\begin{array}{l}57 . \\
33\end{array}$ & \pm 8.78 & $\begin{array}{l}57 . \\
34\end{array}$ & +9.37 & $\begin{array}{l}57 . \\
31\end{array}$ & \pm 8.32 & $\begin{array}{c}0.991 \\
*\end{array}$ & $\begin{array}{l}53 . \\
58\end{array}$ & $=6.61$ & $\begin{array}{l}58 . \\
69\end{array}$ & \pm 9.15 & $\begin{array}{c}0.084 \\
*\end{array}$ & $\begin{array}{l}53 . \\
58\end{array}$ & $\begin{array}{r} \pm 6 \\
61\end{array}$ & $\begin{array}{l}58 . \\
69\end{array}$ & \pm 9.15 & \\
\hline Median & 55 & (43- & 55 & (44- & 8.3 & (43- & & 52. & (44- & 56 & (43- & & 52. & (44- & 56 & (43- & \\
\hline
\end{tabular}




\begin{tabular}{|c|c|c|c|c|c|c|c|c|c|c|c|c|c|c|c|c|c|}
\hline (Range) & & $80)$ & & \begin{tabular}{|l|} 
\\
\end{tabular} & 2 & \multicolumn{2}{|c|}{ 75) } & \multicolumn{2}{|c|}{\begin{tabular}{|l|l|}
50 & $65)$ \\
\end{tabular}} & \multicolumn{3}{|c|}{ 80) } & \multicolumn{2}{|c|}{\begin{tabular}{|l|l|}
50 & $65)$ \\
\end{tabular}} & \multicolumn{3}{|c|}{$80)$} \\
\hline $36-45$ & 3 & $(6.7$ & 2 & $\mid(66.7)$ & 1 & $(33.3$ & 0.856 & 2 & $(66.7$ & 1 & $(33.3$ & 0.165 & 2 & $(66.7$ & 1 & $(33.3$ & 0.165 \\
\hline years & & $\%)$ & & $\%)$ & & $\%)$ & $\S$ & & $\%)$ & & $\%)$ & $\S$ & & $\%)$ & & $\%)$ & $\S$ \\
\hline $\begin{array}{l}46-60 \\
\text { years }\end{array}$ & 28 & $\begin{array}{c}(62.2 \\
\%)\end{array}$ & 14 & $\begin{array}{c}(50 \% \\
)\end{array}$ & 14 & $\begin{array}{c}(50 \% \\
)\end{array}$ & & 8 & $\begin{array}{c}(28.6 \\
\%)\end{array}$ & 20 & $\begin{array}{c}(71.4 \\
\%)\end{array}$ & & 8 & $\begin{array}{c}(28.6 \\
\%)\end{array}$ & 20 & $\begin{array}{c}(71.4 \\
\%)\end{array}$ & \\
\hline$>60$ years & 14 & $\begin{array}{c}(31.1 \\
\%)\end{array}$ & 7 & $\begin{array}{c}(50 \%) \\
)\end{array}$ & 7 & $\begin{array}{c}(50 \% \\
)\end{array}$ & & 2 & $\begin{array}{c}(14.3 \\
\%)\end{array}$ & 12 & $\begin{array}{c}(85.7 \\
\%)\end{array}$ & & 2 & $\begin{array}{c}(14.3 \\
\%)\end{array}$ & 12 & $\begin{array}{c}(85.7 \\
\%)\end{array}$ & \\
\hline Sex & & & & & & & & & & & & & & & & & \\
\hline Male & 20 & (44.4 & 10 & $(50 \%$ & 10 & $(50 \%$ & 0.894 & 5 & $(25 \%$ & 15 & (75\% & 0.821 & 5 & $(25 \%$ & 15 & $(75 \%$ & 0.821 \\
\hline & & $\%)$ & & ) & & ) & $\S$ & & ) & & ) & $\S$ & & ) & & ) & $\S$ \\
\hline Female & 25 & $\begin{array}{c}(55.6 \\
\%)\end{array}$ & 13 & $\begin{array}{c}(52 \% \\
)\end{array}$ & 12 & $\begin{array}{c}(48 \% \\
)\end{array}$ & & 7 & $\begin{array}{c}28 \% \\
)\end{array}$ & 18 & $\begin{array}{c}(72 \% \\
)\end{array}$ & & 7 & $\begin{array}{c}28 \% \\
)\end{array}$ & 18 & $\begin{array}{c}(72 \% \\
)\end{array}$ & \\
\hline Location & & & & & & & & & & & & & & & & & \\
\hline Rt colon & 14 & $(31.1$ & 7 & $(50 \%$ & 7 & $50 \%$ & 0.667 & 3 & (21.4 & 11 & (78.6 & 0.177 & 3 & $(21.4$ & 11 & (78.6 & 0.177 \\
\hline & & $\%)$ & & ) & & ) & $\S$ & & $\%)$ & & $\%)$ & $\S$ & & $\%)$ & & $\%)$ & $\S$ \\
\hline $\begin{array}{l}\text { Transverse } \\
\text { colon }\end{array}$ & 5 & $\left(\begin{array}{c}(11.1 \\
\%)\end{array}\right.$ & 2 & $\begin{array}{c}(40 \% \\
)\end{array}$ & 3 & $\begin{array}{c}60 \% \\
)\end{array}$ & & 2 & $\begin{array}{c}(40 \% \\
)\end{array}$ & 3 & $\begin{array}{c}60 \% \\
)\end{array}$ & & 2 & $\begin{array}{c}(40 \% \\
)\end{array}$ & 3 & $\begin{array}{c}60 \% \\
)\end{array}$ & \\
\hline Lt colon & 8 & $\begin{array}{c}(17.8 \\
\%)\end{array}$ & 3 & $\left.\begin{array}{c}(37.5 \\
\%\end{array}\right)$ & 5 & $\begin{array}{c}62.5 \\
\%)\end{array}$ & & 0 & $(0 \%)$ & 8 & $\begin{array}{c}(100 \\
\%)\end{array}$ & & 0 & $(0 \%)$ & 8 & $\begin{array}{c}(100 \\
\%)\end{array}$ & \\
\hline Rectum & 18 & $\begin{array}{c}(40 \% \\
)\end{array}$ & 11 & \begin{tabular}{|c|}
$(61.1$ \\
$\%)$
\end{tabular} & 7 & $\begin{array}{c}(38.9 \\
\%)\end{array}$ & & 7 & $\begin{array}{c}(38.9 \\
\%)\end{array}$ & 11 & $\begin{array}{c}(61.1 \\
\%)\end{array}$ & & 7 & $\left.\begin{array}{c}(38.9 \\
\%\end{array}\right)$ & 11 & $\begin{array}{c}(61.1 \\
\%)\end{array}$ & \\
\hline Number & & & & & & & & & & & & & & & & & \\
\hline Single & 39 & $(86.7$ & 20 & $(51.3$ & 19 & (48.7) & 1.000 & 11 & $(28.2$ & 28 & $(71.8$ & 1.000 & 11 & $(28.2$ & 28 & (71.8 & 1.000 \\
\hline & & $\%)$ & & $\%)$ & & $\%)$ & $\S$ & & $\%)$ & & $\%)$ & $\S$ & & $\%)$ & & $\%)$ & $\S$ \\
\hline Multiple & 6 & $\begin{array}{c}(13.3 \\
\%)\end{array}$ & 3 & $\begin{array}{c}(50 \% \\
)\end{array}$ & 3 & $\begin{array}{c}(50 \% \\
)\end{array}$ & & 1 & $\begin{array}{c}(16.7 \\
\%)\end{array}$ & 5 & $\begin{array}{c}(83.3 \\
\%)\end{array}$ & & 1 & $\begin{array}{c}(16.7 \\
\%)\end{array}$ & 5 & $\begin{array}{c}(83.3 \\
\%)\end{array}$ & \\
\hline $\begin{array}{l}\text { Gross } \\
\text { pattern }\end{array}$ & & & & & & & & & & & & & & & & & \\
\hline Ulcerative & 22 & (50\% & 14 & $(63.6$ & 8 & (36.4) & 0.308 & 7 & (31.8 & 15 & 68.2 & 0.794 & 7 & (31.8 & 15 & $(68.2$ & 0.794 \\
\hline & & ) & & $\%)$ & & $\%)$ & $\S$ & & $\%)$ & & $\%)$ & $\S$ & & $\%)$ & & $\%)$ & $\S$ \\
\hline Fungating & 9 & $\begin{array}{c}(20.5 \\
\%)\end{array}$ & 4 & $\begin{array}{c}(44.4 \\
\%)\end{array}$ & 5 & $\begin{array}{c}(55.6 \\
\%)\end{array}$ & & 2 & $\begin{array}{c}(22.2 \\
\%)\end{array}$ & 7 & $\begin{array}{c}(77.8 \\
\%)\end{array}$ & & 2 & $\begin{array}{c}(22.2 \\
\%)\end{array}$ & 7 & $\begin{array}{c}(77.8 \\
\%)\end{array}$ & \\
\hline Annular & 13 & $\begin{array}{c}(29.5 \\
\%)\end{array}$ & 5 & $\begin{array}{c}(38.5 \\
\%)\end{array}$ & 8 & $\begin{array}{c}(61.5 \\
\%)\end{array}$ & & 3 & $\begin{array}{c}(23.1 \\
\%)\end{array}$ & 10 & $\begin{array}{c}(76.9 \\
\%)\end{array}$ & & 3 & $\begin{array}{c}(23.1 \\
\%)\end{array}$ & 10 & $\begin{array}{c}(76.9 \\
\%)\end{array}$ & \\
\hline Size $(\mathrm{cm})$ & & & & & & & & & & & & & & & & & \\
\hline Mean \pm & 74. & \pm 18.5 & 79. & \pm 15.6 & 68. & \pm 20.0 & 0.055 & 79. & \pm 18.6 & 72. & \pm 18.3 & 0.242 & 79. & \pm 18.6 & 72. & \pm 18.3 & 0.242 \\
\hline SD & 17 & 2 & 34 & 1 & 77 & 9 & $*$ & 58 & 4 & 21 & 6 & * & 58 & 4 & 21 & 6 & $*$ \\
\hline $\begin{array}{l}\text { Median } \\
\text { (Range) }\end{array}$ & 75 & $\begin{array}{l}30- \\
120)\end{array}$ & 80 & \begin{tabular}{|l|}
$(55-$ \\
$120)$
\end{tabular} & 70 & \begin{tabular}{|l|}
$(30-$ \\
$100)$
\end{tabular} & & 80 & \begin{tabular}{|l|}
$(55-$ \\
$120)$
\end{tabular} & 70 & \begin{tabular}{|l|}
$(30-$ \\
$100)$ \\
\end{tabular} & & 80 & \begin{tabular}{|c|}
$(55-$ \\
$120)$
\end{tabular} & 70 & $\begin{array}{l}(30- \\
100)\end{array}$ & \\
\hline $10-50 \mathrm{~mm}$ & 9 & (13.3 & 1 & (16.7) & 5 & $(83.3$ & 0.096 & 0 & $(0 \%)$ & 6 & $(100$ & 0.171 & 0 & $(0 \%)$ & 6 & $(100$ & 0.171 \\
\hline & & $\%)$ & & $\%)$ & & $\%)$ & $\delta$ & & & & $\%)$ & $\S$ & & & & $\%)$ & $\delta$ \\
\hline$>50 \mathrm{~mm}$ & 39 & $\begin{array}{c}86.7 \\
\%)\end{array}$ & 22 & $\mid \begin{array}{c}(56.4 \\
\%)\end{array}$ & 17 & $\begin{array}{c}(43.6 \\
\%)\end{array}$ & & 12 & $\begin{array}{c}(30.8 \\
\%)\end{array}$ & 27 & $\begin{array}{c}(69.2 \\
\%)\end{array}$ & & 12 & $\begin{array}{c}(30.8 \\
\%)\end{array}$ & 27 & $\begin{array}{c}69.2 \\
\%)\end{array}$ & \\
\hline Grade & & & & & & & & & & & & & & & & & \\
\hline Grade 1 & 31 & (68.9 & 16 & $(51.6$ & 15 & (48.4) & 0.759 & 9 & $(29 \%$ & 22 & (71\% & 0.974 & 9 & $(29 \%$ & 22 & (71\%) & 0.974 \\
\hline & & $\%)$ & & $\%)$ & & $\%)$ & $t$ & & ) & & ) & $t$ & & ) & & ) & $t$ \\
\hline Grade 2 & 9 & $\begin{array}{c}20 \% \\
)\end{array}$ & 5 & $\left.\begin{array}{c}(55.6 \\
\%\end{array}\right)$ & 4 & $\begin{array}{c}(44.4 \\
\%)\end{array}$ & & 1 & $\begin{array}{c}(11.1 \\
\%)\end{array}$ & 8 & $\begin{array}{c}(88.9 \\
\%)\end{array}$ & & 1 & $\begin{array}{c}(11.1 \\
\%)\end{array}$ & 8 & $\begin{array}{c}(88.9 \\
\%)\end{array}$ & \\
\hline Grade 3 & 5 & $\begin{array}{c}(11.1 \\
\%)\end{array}$ & 2 & $\begin{array}{c}(40 \% \\
)\end{array}$ & 3 & $\begin{array}{c}60 \% \\
)\end{array}$ & & 2 & $\begin{array}{c}(40 \% \\
)\end{array}$ & 3 & $\begin{array}{c}60 \% \\
)\end{array}$ & & 2 & $\begin{array}{c}(40 \% \\
)\end{array}$ & 3 & $\begin{array}{c}60 \% \\
)\end{array}$ & \\
\hline $\mathrm{T}$ & & & & & & & & & & & & & & & & & \\
\hline T1 & 2 & $(4.4$ & 1 & $50 \%$ & 1 & $50 \%$ & 0.791 & 0 & $(0 \%)$ & 2 & $(100$ & 0.925 & 0 & $(0 \%)$ & 2 & $(100$ & 0.925 \\
\hline & & $\%)$ & & ) & & & $t$ & & & & $\%)$ & \pm & & & & $\%)$ & 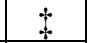 \\
\hline $\mathrm{T} 2$ & 3 & $(6.7$ & 2 & 66.7 & 1 & (33.3 & & 2 & $(66.7$ & 1 & $(33.3$ & & 2 & 66.7 & 1 & $(33.3$ & \\
\hline
\end{tabular}




\begin{tabular}{|c|c|c|c|c|c|c|c|c|c|c|c|c|c|c|c|c|c|}
\hline & & $\%)$ & & $\%)$ & \multicolumn{3}{|c|}{$\%)$} & & $\%)$ & & \multicolumn{2}{|l|}{ \%) } & \multicolumn{2}{|r|}{ \%) } & \multicolumn{3}{|c|}{$\%)$} \\
\hline T3 & 40 & $\begin{array}{c}(88.9 \\
\%)\end{array}$ & 20 & $\begin{array}{c}(50 \% \\
)\end{array}$ & 20 & $\begin{array}{c}(50 \% \\
)\end{array}$ & & 10 & $\begin{array}{c}(25 \% \\
)\end{array}$ & 30 & $\begin{array}{c}(75 \% \\
)\end{array}$ & & 10 & $\begin{array}{c}(25 \% \\
)\end{array}$ & 30 & $\begin{array}{c}(75 \% \\
)\end{array}$ & \\
\hline $\mathrm{N}$ & & & & & & & & & & & & & & & & & \\
\hline N0 & 6 & (13.3 & 4 & $(66.7$ & 2 & $(33.3$ & 0.665 & 3 & $(50 \%$ & 3 & $(50 \%$ & 0.319 & 3 & $(50 \%$ & 3 & $(50 \%$ & 0.319 \\
\hline & & $\%)$ & & $\%)$ & & $\%)$ & $\S$ & & ) & & ) & $\S$ & & ) & & ) & $\S$ \\
\hline N1 & 39 & $\begin{array}{c}(86.7 \\
\%)\end{array}$ & 19 & $\begin{array}{c}(48.7 \\
\%)\end{array}$ & 20 & $\begin{array}{c}(51.3 \\
\%)\end{array}$ & & 9 & $\begin{array}{c}(23.1 \\
\%)\end{array}$ & 30 & $\begin{array}{c}(76.9 \\
\%)\end{array}$ & & 9 & $\begin{array}{c}(23.1 \\
\%)\end{array}$ & 30 & $\begin{array}{c}(76.9 \\
\%)\end{array}$ & \\
\hline Stage & & & & & & & & & & & & & & & & & \\
\hline Stage I & 2 & $\begin{array}{c}(4.4 \\
\%)\end{array}$ & 1 & $\begin{array}{c}(50 \%) \\
)\end{array}$ & 1 & $\begin{array}{c}50 \% \\
)\end{array}$ & $\begin{array}{c}0.791 \\
\pm\end{array}$ & 0 & $(0 \%)$ & 2 & $\begin{array}{c}(100 \\
\%)\end{array}$ & $\begin{array}{c}0.925 \\
\pm\end{array}$ & 0 & $(0 \%)$ & 2 & $\begin{array}{c}(100 \\
\%)\end{array}$ & $\begin{array}{c}0.925 \\
+\end{array}$ \\
\hline Stage II & 3 & \begin{tabular}{|c|}
6.7 \\
$\%)$
\end{tabular} & 2 & $\left.\begin{array}{c}(66.7 \\
\%\end{array}\right)$ & 1 & $\begin{array}{c}(33.3 \\
\%)\end{array}$ & & 2 & $\begin{array}{c}(66.7 \\
\%)\end{array}$ & 1 & $\begin{array}{c}(33.3 \\
\%)\end{array}$ & & 2 & $\begin{array}{c}(66.7 \\
\%)\end{array}$ & 1 & $\begin{array}{c}(33.3 \\
\%)\end{array}$ & \\
\hline Stage III & 40 & $\begin{array}{c}(88.9 \\
\%)\end{array}$ & 20 & $\begin{array}{c}(50 \% \\
)\end{array}$ & 20 & $\begin{array}{c}(50 \% \\
)\end{array}$ & & 10 & $\begin{array}{c}(25 \% \\
)\end{array}$ & 30 & $\begin{array}{c}(75 \% \\
)\end{array}$ & & 10 & $\begin{array}{c}(25 \% \\
)\end{array}$ & 30 & $\begin{array}{c}(75 \% \\
)\end{array}$ & \\
\hline $\begin{array}{l}\text { Nuclear } \beta \\
\text { catenin }\end{array}$ & & & & & & & & & & & & & & & & & \\
\hline Positive & 22 & $\begin{array}{c}(48.9 \\
\%)\end{array}$ & & & & & & 0 & $(0 \%)$ & 22 & $\left.\begin{array}{c}(100 \\
\%\end{array}\right)$ & & 0 & $(0 \%)$ & 22 & $\begin{array}{c}(100 \\
\%)\end{array}$ & \\
\hline Negative & 23 & $\left(\begin{array}{c}51.1 \\
\%)\end{array}\right.$ & & & & & & 12 & $\begin{array}{c}(52.2 \\
\%)\end{array}$ & 11 & $\begin{array}{c}(47.8 \\
\%)\end{array}$ & $\begin{array}{c}<0.00 \\
1 \S\end{array}$ & 12 & $\begin{array}{c}(52.2 \\
\%)\end{array}$ & 11 & $\begin{array}{c}(47.8 \\
\%)\end{array}$ & $\begin{array}{c}<0.00 \\
1 \S\end{array}$ \\
\hline $\begin{array}{l}\text { Cytoplasmi } \\
\text { c } \beta \text { catenin }\end{array}$ & & & & & & & & & & & & & & & & & \\
\hline Positive & 12 & $\begin{array}{c}(26.7 \\
\%)\end{array}$ & 12 & $\begin{array}{c}(100 \\
\%)\end{array}$ & 0 & $(0 \%)$ & $\begin{array}{c}0.00 \\
1 \S\end{array}$ & & & & & & 12 & $\begin{array}{c}(100 \\
\%)\end{array}$ & 0 & $(0 \%)$ & \begin{tabular}{|c|}
$<0.00$ \\
$1 \S$
\end{tabular} \\
\hline Negative & 33 & $\begin{array}{c}(73.3 \\
\%) \\
\end{array}$ & 11 & $\begin{array}{c}(33.3 \\
\%)\end{array}$ & 22 & $\begin{array}{c}(66.7 \\
\%)\end{array}$ & & & & & & & 0 & $(0 \%)$ & 33 & $\begin{array}{c}(100 \\
\%)\end{array}$ & \\
\hline $\begin{array}{l}\text { Membrano } \\
\text { us } \beta \text { catenin }\end{array}$ & & & & & & & & & & & & & & & & & \\
\hline Positive & 12 & $\begin{array}{c}(26.7 \\
\%)\end{array}$ & 12 & $\begin{array}{c}(100 \\
\%)\end{array}$ & 0 & $(0 \%)$ & $\begin{array}{c}<0.00 \\
1 \S\end{array}$ & 12 & $\begin{array}{c}(100 \\
\%)\end{array}$ & 0 & $(0 \%)$ & $\begin{array}{c}<0.00 \\
1 \S\end{array}$ & & & & & \\
\hline Negative & 33 & $\begin{array}{c}(73.3 \\
\%)\end{array}$ & 11 & $\begin{array}{c}(33.3 \\
\%)\end{array}$ & 22 & $\begin{array}{c}66.7 \\
\%)\end{array}$ & & 0 & $(0 \%)$ & 33 & $\begin{array}{c}(100 \\
\%)\end{array}$ & & & & & & \\
\hline
\end{tabular}

- Categorical variables were expressed as number(percentage), continuous variables were expressed as mean \pm SD \& median (range).

- * Independent samples Student's t-test; $\$$ Chi-square test for trend; §Chi-square test; $p<0.05$ is significant.

Table (4):- correlation between Fascin 1 and $\beta$-catenine expression in colorectal cancer

\begin{tabular}{|c|c|c|c|c|c|c|}
\hline \multirow{2}{*}{\multicolumn{7}{|c|}{$\begin{array}{l}\beta \text { - catenin * Fascin 1Crosstabulation } \\
\text { Count }\end{array}$}} \\
\hline & & & & & & \\
\hline & & \multicolumn{4}{|c|}{ Fascin1 } & \multirow{2}{*}{ Total } \\
\hline & & .00 & 1.00 & 2.00 & 3.00 & \\
\hline \multirow[t]{4}{*}{$\beta$ catenin } & 0.00 & 25 & 3 & 1 & 0 & 29 \\
\hline & 1.00 & 4 & 3 & 2 & 0 & 9 \\
\hline & 2.00 & 2 & 2 & 0 & 2 & 6 \\
\hline & 3.00 & 0 & 1 & 0 & 0 & 1 \\
\hline \multicolumn{2}{|l|}{ Total } & 31 & 9 & 3 & 2 & 45 \\
\hline
\end{tabular}

- $\quad$ Sperman correlation $.528 \mathrm{P}$ value $<0.001$. 


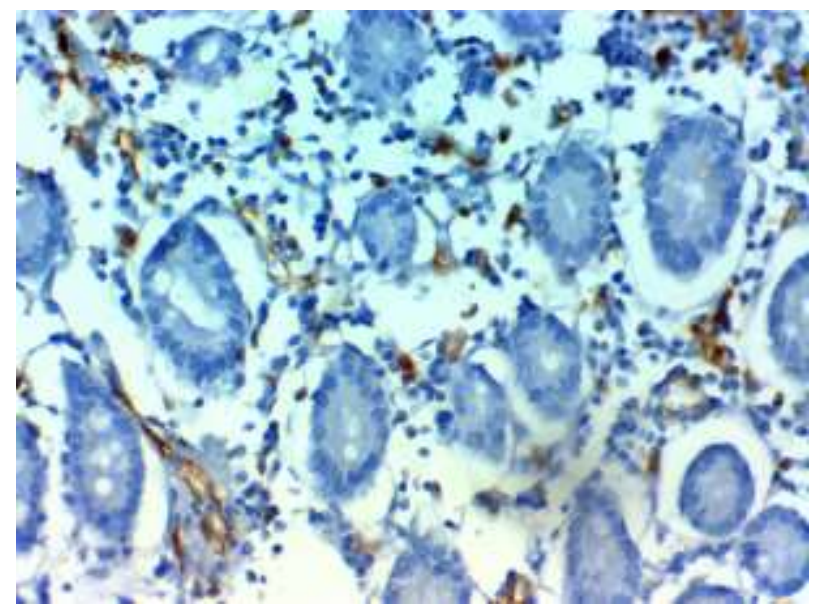

Fig 1 a

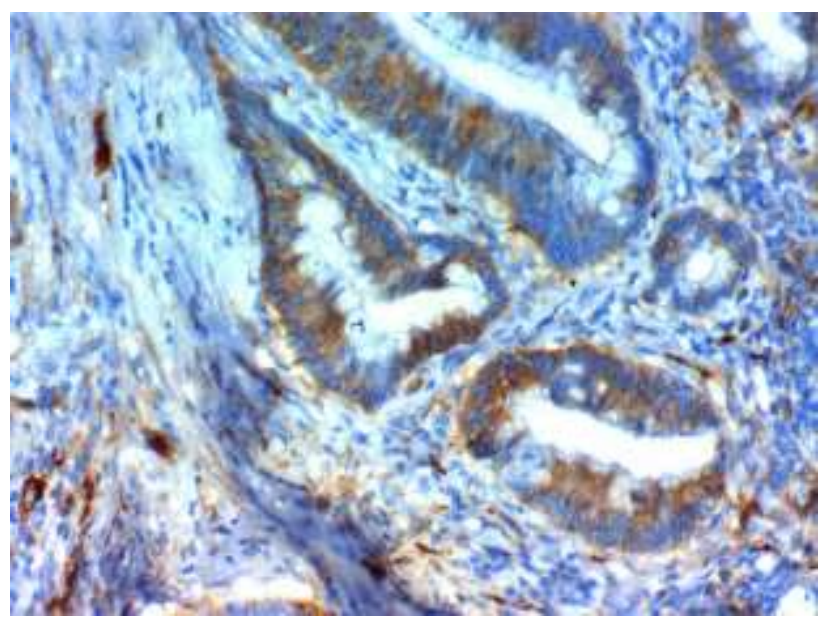

Fig $1 b$

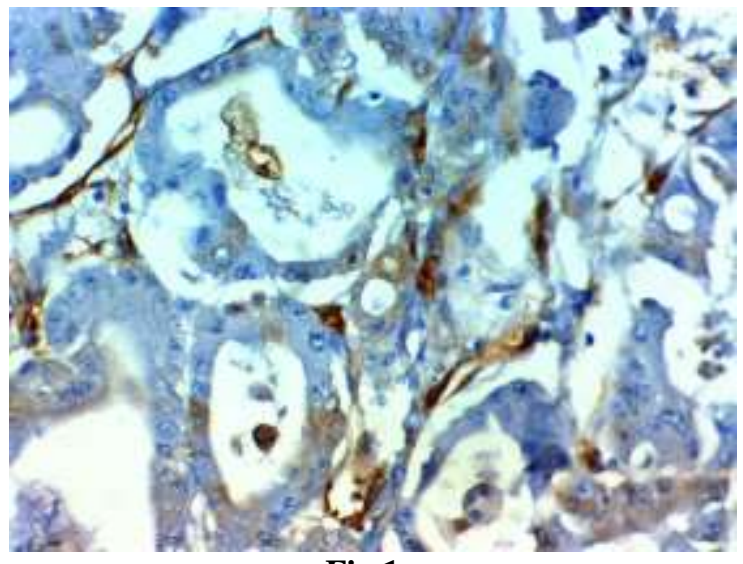

Fig 1 c 


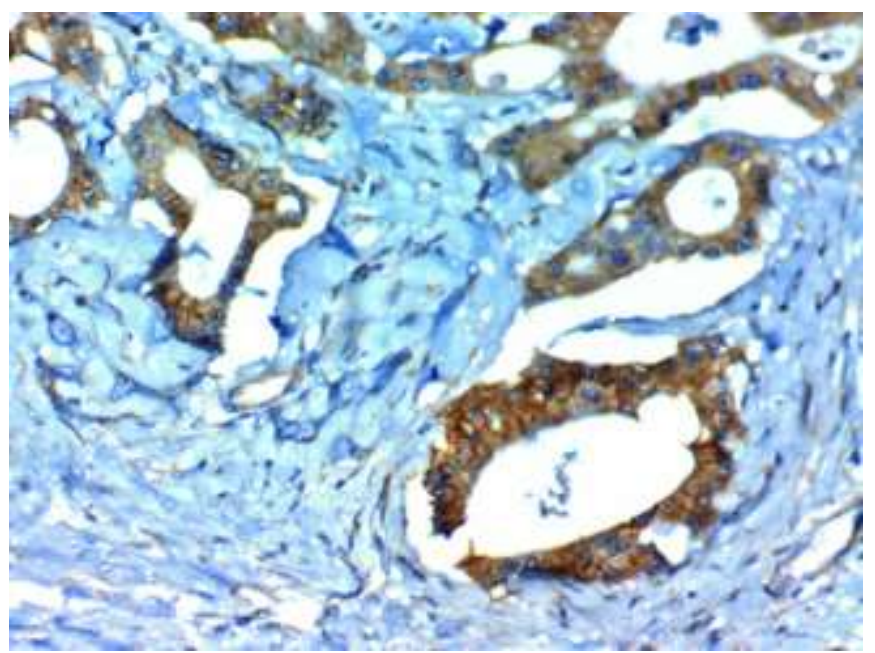

Fig 1 d

Fig. 1: fascin 1 in cancer colon and adenomatous polyps

a -Negative expression of fascin 1 in normal mucosa (ABC, DAB x400).

b - Positive sever cytoplasmic expression $(+3)$ of Fascin 1 in colonic adenomatous polyp (ABC, DABx400).

c- Positive moderate cytoplasmic expression $(+2)$ of Fascin1 in cancer colon $(\mathrm{ABC}, \mathrm{DABx} 400)$.

d- Positive severe cytoplasmic expression(+3) of Fascin 1 1 in invasive front of tumor (ABC, DABx400).

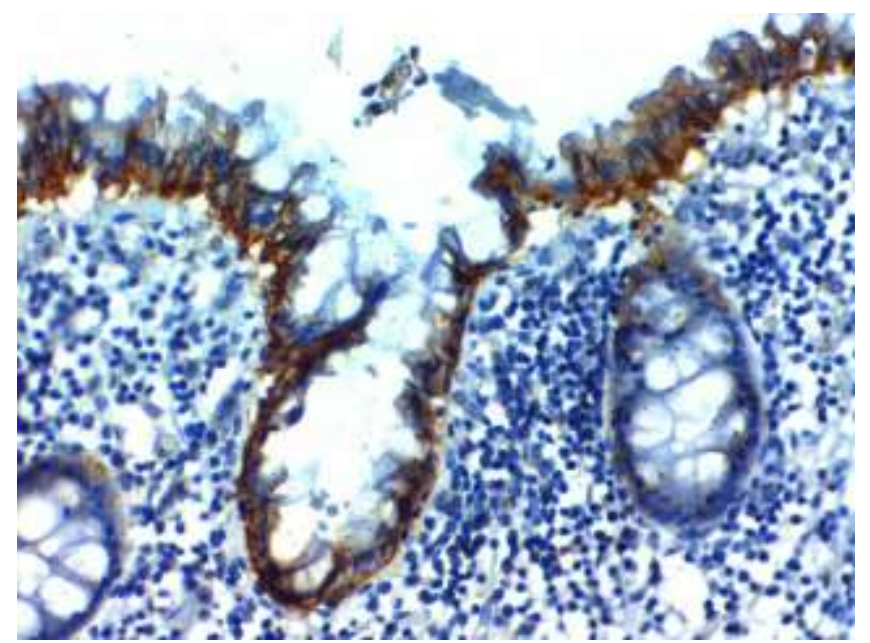

Fig 2 a

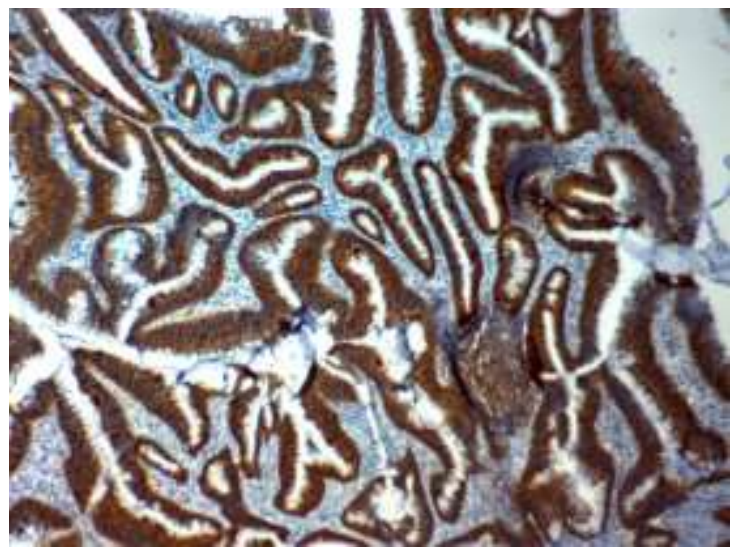

Fig 2 b 


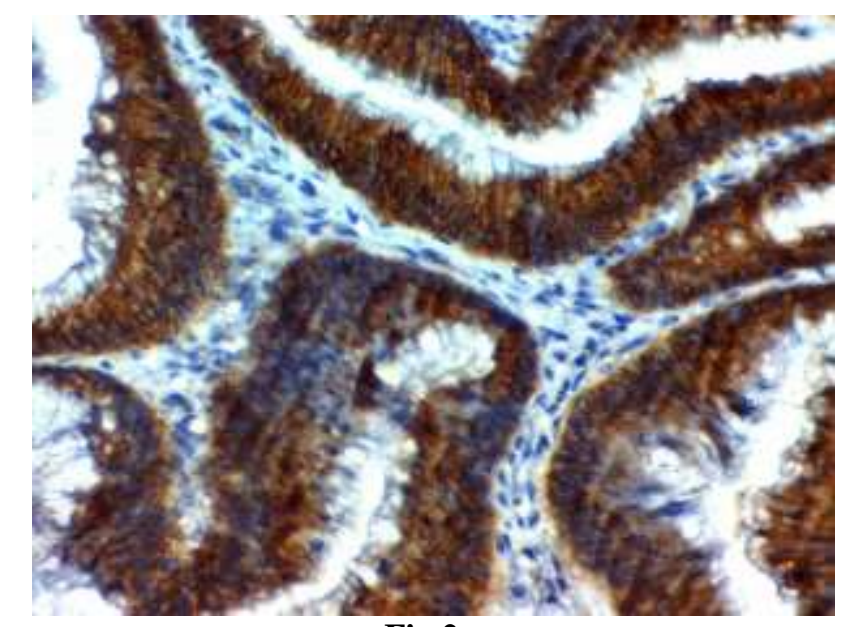

Fig 2 c

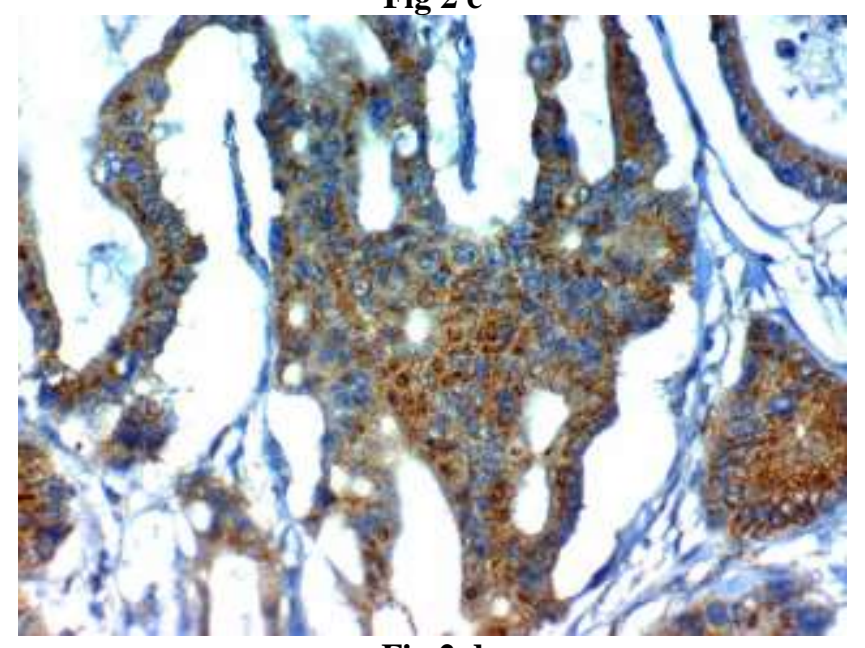

Fig 2 d

Fig. 2: $\beta$ - catenine in cancer colon

a-Strong positive membranous expression of $\beta$ - catenine in normal mucosa (ABC, DABx400).

b. - Colonic adenomatous polyp showing strong cytoplasmic and membranous immunostaining of $\beta$ - catenine $(\mathrm{ABC}, \mathrm{DAB} \times 100$

c- - High power field of previous image (ABC, DABx400).

d- Aberrant high nuclear and cytplasmic expression of $\beta$ - catenine in addition to memberance expression in cancer colon (ABC, DABx 400).

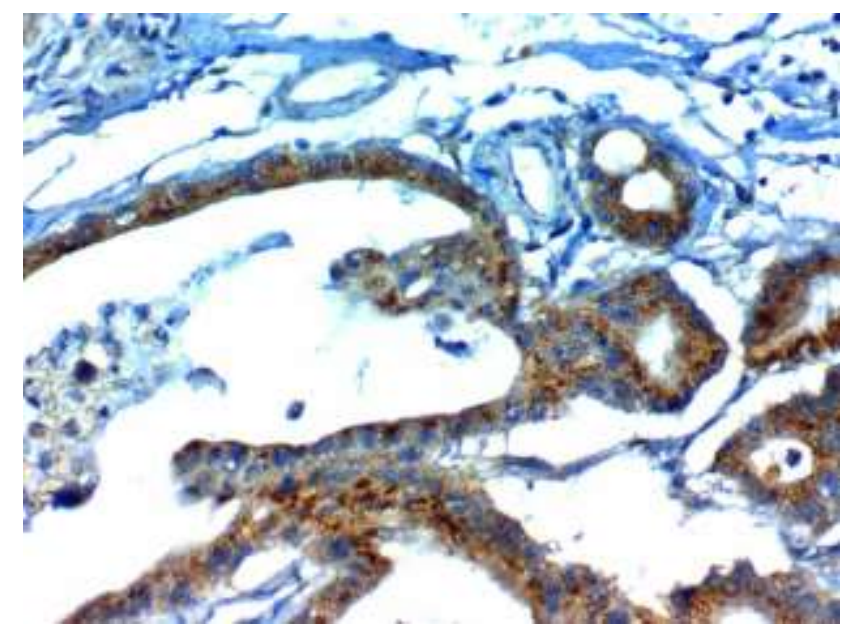

Fig 3 a 


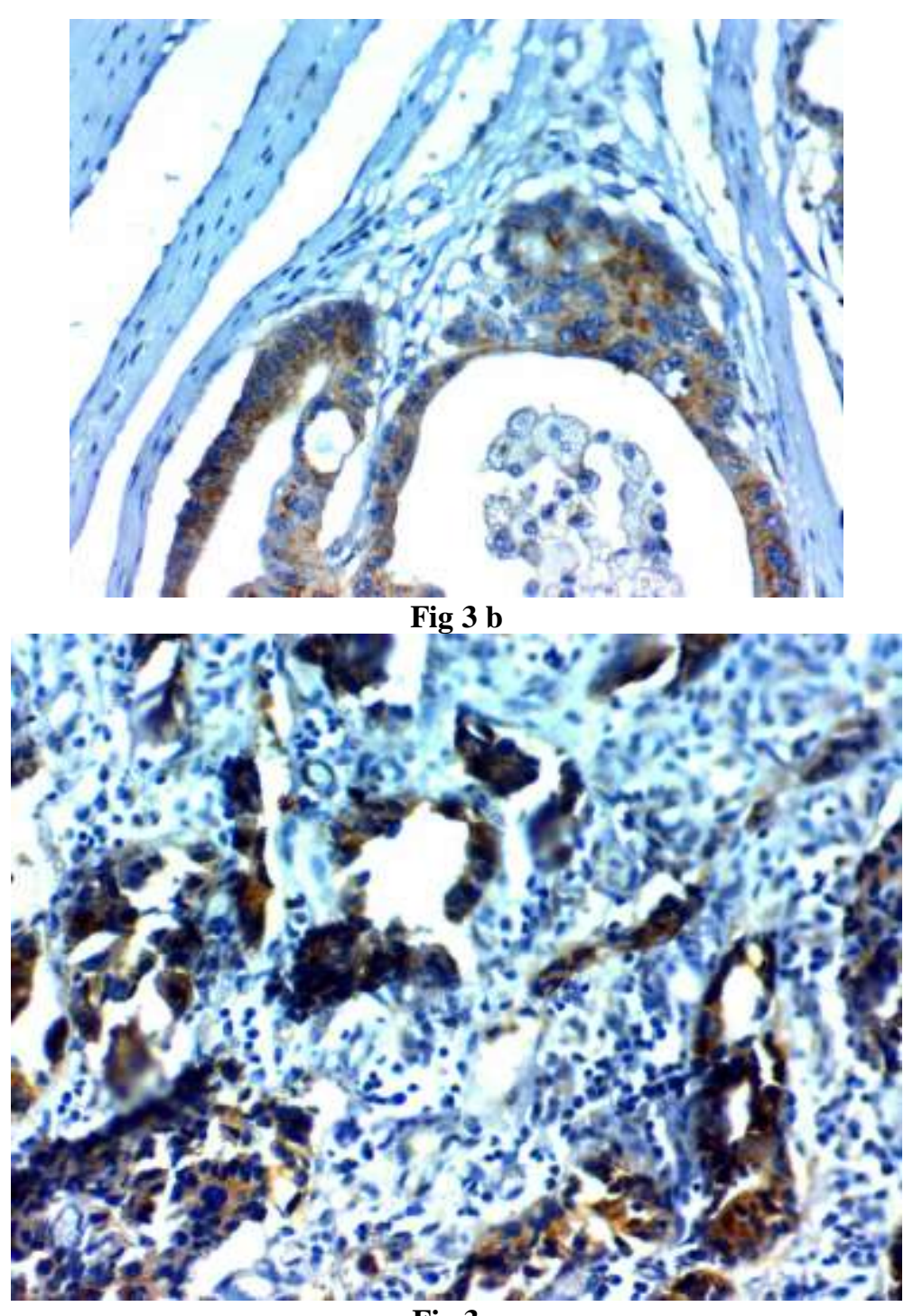

Fig3: $\beta$ - catenine in cancer colon

\section{Fig 3 c}

a. - Positive nuclear and cytoplasmic expression of $\beta$ - catenine in cancer colon (ABC, DAB x400).

b- -Positive expression of $\beta$ - catenine in invasive front of tumor $(\mathrm{ABC}, \mathrm{DAB} \times 400)$

c- Positive cytoplasmic expression of $\beta$ - catenine in moderately differentiated adenocarcinoma(ABC, DABx400).

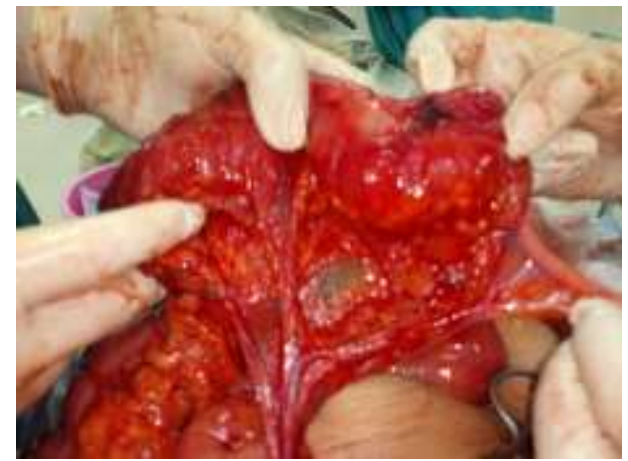

Fig 4 A 


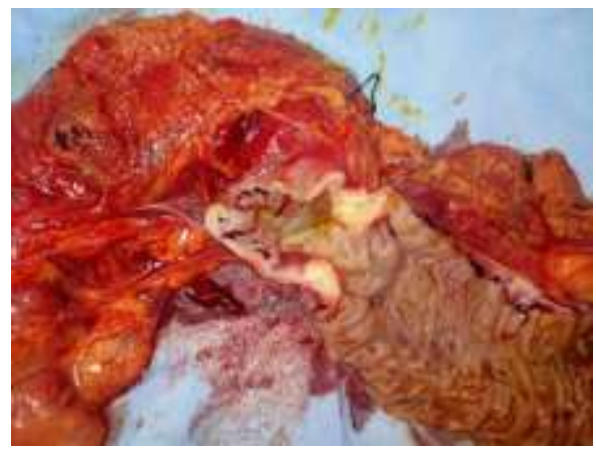

Fig 4 B

Fig 4:- gross description of CRC

Fig $4 \mathrm{~A}$; transverse colectomy was done for fungating colon adenocarcinoma in the transverse colon

Fig 4 B; proctocolectomy done for annular CRC

\section{Discussion:-}

Fascin 1 binds beta-catenin, a molecule the Wnt signaling pathway.Fascin1expression was high in several types of transformed epithelial cell lines and in several solidtumors[8].

Fascin 1expression in malignant colonic cells increased their migration and invasion in cell culture and caused cell propagation and metastasis in vivo. on the contrary, the inhibition of fascinactivity by interfering RNA decreased cell invasion[33].

In thisstudy, no immunohistochemical staining of Fascin 1was detected in the normal colonic epithelial cells adjacent to the tumor, in accordance with previous studies by.Jawhari and Hashimoto[8,18].

We detectFascin 1 positive expression in $40 \%$ of colorectal adenomatous polyp. The results are different from that ofHashimoto[19] who found Fascin 1expression in 16\% of adenomas. The difference may be due to different sample size (107 cases in their studied group).

In this study,no significant difference was found between Fascin 1 expression in adenomas and carcinoma,in contrast,Tasi and Hashimoto[20,10]found that higher Fascin 1expression were significantly associated with high grade dysplasia in adenoma of the colon.

This study also revealed that Fascin 1 staining $31.1 \%$ of colorectal adenocarcinomas. The results are close to that ofOzerhan and Hashimoto. 2006 and Hashimoto 2011[21,10,19] who detect Fascin1 expression in 35.3\%, 26\% and26\%) of their studied cases respectively however ,Puppa and Jeong[11,13],found that Fascin 1 was detected in $71 \%$ of and $79.7 \%$ of their studied cases respectively.

In the current study, no significant differencewas identified between Fascin 1 expression and gender but associated with age the results similar to Hashimoto 2006[10] .However, in a study by puppa[11], Fascin 1 correlated significantly with the female sex.

We found Fascin 1 expression was associated withhigh grade of the tumors $(\mathrm{p}=0.0001)$, similar toOzerhan[21]. andVignjevicAlso Tsai [7,20] who found that higher Fascin 1immunostaining were significantly associated with high-grade of colonic carcinomas.

In this work,no association between Fascin 1 expression and the tumor stage of colorectal adenocarcinoma but there is association with L.N state $(\mathrm{p}=0.0497)$. Results parallel toHashimoto 2006[10] but Tsai [20]andPuppa [11]found Fascin1 was associated with highTNM stage. This difference may be due to small number of cases.

This study showed strong Fascin 1 at the invasive front this was also explained byJung[22].Migratingcells commonly concentrated at the invading border of tumors. Thus, tumors having a large portion of Fascin1-positive cells might have a high potential for invasive manners. 
Jawhari andShonukan[8,9], suggesting that Fascin 1 can enhance the directional motility of cells. Also high expression of fascin in colonic epithelial or its diminution in esophageal carcinoma cells correlated, respectively, with increased or decreased cell proliferation in culture.Jawhariand Xie $[8,23]$

Fascin 1 expression is associated with high stage in breast carcinomas,Fascin1 associated with metastatic cancer lung, Minn[24].Fascin 1 expression also with an aggressive type of colorectal adenocarcinomas.

$\beta$-catenin signaling pathway plays arole in the carcinogenesis of colorectal carcinoma. Nuclear accumulation of $\beta$ catenin is an important step in colorectal tumorogenesis, Wongand chung [25,26]. Wong [27]noticed that the expression of nuclear $\beta$-catenin increased during the development of carcinoma. There is also evidence that carcinoma in situ CRCs are frequently associated with high nuclear $\beta$-catenin expression [28].

The current study showed $\beta$-catenin in normal colonic epithelium, neoplastic cells establishedashift from a membranous expression to a more widespread distribution (membranous, cytoplasmic, and nuclear) in malignant lesions. This is in agree with previous studies by Mikami and Horkko [29,30]describing $\beta$-catenin expression in cancer cells with this type of altered pattern.

In this study no nuclear $\beta$ - catenineexpression in normal mucosa this is in concordance with studies byRoca [31]and Ougolkov [5].

In our study There is statistically significant difference between cytoplasmic $\beta$ - -catenin expression and adenomatous polyp $(\mathrm{p}=0.0001)$. Wong [27]alsonoticed no nuclear $\beta$-catenin accumulation in normal tissues, whereas it was seen in $8 \%$ of polyps, $92 \%$ of adenomas, and $100 \%$ of carcinomas.

In our studyatypical cytoplasmic and nuclear $\beta$-catenin wasseen in $26.7 \%$ and $48.9 \%$ of cases of carcinoma. the results go withHashimoto [19], who observed nuclear expression in 48\% of the cancer. Also similar toStanczak[32] who detected unusual cytoplasmic and nuclear $\beta$-catenin in $51.5 \%(34 / 66)$ and $31.8 \%$ (21/66) of patients, respectively

Results parallel toWong[27]who observed no nuclear $\beta$-catenin accumulation in normal tissues, whereas it was present in $8 \%$ of polyps, $92 \%$ of adenomas, and $100 \%$ of carcinomas.

Expression of nuclear $\beta$ catenin amplified significantly during the progression from normal to carcinoma. Wong[25] In the current study significant relation was found between cytoplasmic and membrance expression of $\beta$ - catenine ( $p$ value $<0.001$ ) and between cytoplasmic and nuclear expression of $\beta$ - catenine ( $\mathrm{p}$ value $<0.001)$.

In this study, In the inner more differentiated regions of tumors, $\beta$-catenin staining was detected in the membrane and in the cytoplasm. In the invasive front of tumors, we noticed cytoplasmic and nuclear $\beta$-catenin localization and was associated with strong Fascin1 expression. Fascin 1 expression was high in sheets of invading tumor cells. Results similar to Vignjevic[7], and this explained by $\beta$-catenin-TCF signaling is involved in the regulation of fascinl gene transcription in human colorectal carcinoma

In our study highly significant correlation between both markers, was found this is explained by Fascin 1 has been established that its actin-binding properties are regulated by adhesion receptors and receptor tyrosine kinases similar to studies by. Cohan andJawhariand Ross [33,8,34].

Fascin 1 in cancer colon and cultures of colonic cancer cells correlates with the presence of $\beta$-catenin in the nuclei of cells, indicative of its activity in $\beta$-catenin-TCF signaling. Vignjevic[7]and they concluded that Fascin 1 is a new target of $\beta$ - -catenin-TCF signaling. They projected that transient up-regulation of Fascin 1 in colorectal cancer promotes the achievement of migratory and invasive phenotypes that lead to metastasis.

\section{Summary:-}

Positive Fascin1 expression is significantly correlated with L. N state ( $\mathrm{p}=0.0497)$. Both markers are significantly correlated with tumor grade $(\mathrm{p}<<0.001)$. Both markers are significantly correlated with each others. 


\section{Conclusion:-}

Fascin1 has important roles in cell morphology and migration and may represent a potential new marker or therapeutic target for patients with colorectal cancer. Fascin 1 is regulated by $\beta$-catenine. IHC staining of $\beta$-catenin is considered to be ahelpful marker to predict the prognosis in CRC. We recommended more, further studies to investigate the prognostic significance of $\beta$-catenin.

\section{References:-}

1. Siegel RL, Miller KD, Jemal A. Cancer statistics.CA Cancer J Clin. 2015;65:5-29.

2. Ferlay J, Shin HR, Bray F, et al. Estimates of worldwide burden of cancerin: GLOBOCAN 2008. Int J Cancer 2010;127:2893-917.

3. White BD, Chien AJ, Dawson DW.Dysregulation of Wnt/ק-catenin signaling in gastrointestinal cancers.Gastroenterology. 2012;142(2):219-32.

4. Fujimori M, Ikeda S, Shimizu Y, Okajima M, Asahara T. Accumulation of beta-catenin protein and mutations in exon 3 of beta-catenin gene in gastrointestinal carcinoid tumor. Cancer Res. 2001;61:66566659.

5. Ougolkov AV, Yamashita K, Mai M, Minamoto T. Oncogenic beta-catenin and MMP-7 (matrilysin) cosegregate in late-stage clinical colon cancer. Gastroenterology. 2002;122:60-71.

6. Miyamoto S, Endoh Y, Hasebe T, Ishii G, Kodama K, Goya M, Ono M, Saitoh N, Chiba T, Ochiai A. Nuclear beta-catenin accumulation as a prognostic factor in Dukes' D human colorectal cancers. Oncol Rep. 2004;12:245-251.

7. Vignjevic D, Kojima S, Aratyn Y, Danciu O, Svitkina T, Borisy GG. Role of fascinin filopodialprotrusion. J Cell Biol.2006; 174: 863-75.

8. Jawhari AU, Buda A, Jenkins M, et al. Fascin, an actin-bundling protein, modulates colonic epithelial cell invasiveness and differentiation in vitro. Am J Pathol. 2003; 162: 69-80.

9. Shonukan O, Bagayogo I, McCrea P, Chao M, Hempstead B. Neurotrophin-induced melanoma cell migration is mediated through the actin-bundling protein fascin. Oncogene. 2003; 22: 3616-23.

10. Hashimoto Y, Skacel M, Lavery IC, Mukherjee AL, Casey G, Adams JC.Prognostic significance of fascin expression in advanced colorectal cancer: an immunohistochemical study of colorectal adenomas and adenocarcinomas.BMC Cancer2006; 6: 241.

11. Puppa G, Maisonneuve P, Sonzogni A, et al. Independent prognostic value of fascinimmunoreactivity in stage III-IV colonic adenocarcinoma. Br J Cancer 2007; 96: 1118-26.

12. Hsu SM, Raine $L$ and Fanger $H$. Use of avidin-biotin-peroxidase complex (ABC) in immunoperoxidase techniques: a comparison between $\mathrm{ABC}$ and unlabeled antibody (PAP) procedures.J HistochemCytochem 1981; 29:577-580.

13. Jeong M., Jong H., Mee S., Ki J. The Prognostic Significance of Fascin Expression in Colorectal Carcinoma.Intest Res 2010;8(2):117-125.

14. Ru G, Wang $\mathbf{H}, \mathrm{Xu}$ W and Zhao Z: Upregulation of Twist in gastric carcinoma associated with tumor invasion and poor prognosis. PatholOncol Res. 2011;17:341-347.

15. Elzagheid A, Kuopio T, Ilmen M, Collan Y. Prognostication of invasive ductal breast cancer by quantification of E-cadherin immunostaining: the methodology and clinical relevance.Histopathology. 2002;41:127-133.

16. Gao, Z., Lu, C., Wang, M., Han, Y., Guo, L."Differential $\beta$-catenin expression levels are associated with morphological features and prognosis of colorectal cancer". Oncology Letters. 2014: 2069-2076.

17. Baldus S, Mönig S, Huxel S, et al: MUC1 and nuclear beta-catenin are coexpressed at the invasion front of colorectal carcinomas and are both correlated with tumor prognosis. Clin Cancer Res. 2004;10:27902796.

18. Hashimoto Y1, Skacel M, Adams JC.Association of loss of epithelial syndecan-1 with stage and local metastasis of colorectal adenocarcinomas: an immunohistochemical study of clinically annotated tumors.BMC Cancer.2008;30:8:185.

19. Hashimoto Y, Skacel M, Lavery IC, Mukherjee AL, Casey G, Adams JC. prognostic significance of fascin expression in advanced colorectal cancer: an immunohistochemical study of colorectal adenomas and adenocarcinomas. BMCBMC Cancer. 2011;11:488.

20. Tsai W, Chao Y, Sheu L, Chang J, Nieh S, Jin JS. Overexpression of fascin-1 in advanced colorectal adenocarcinoma: tissue microarray analysis of immunostaining scores with clinicopathological parameters. Dis Markers. 2007;23:153-60. 
21. Ozerhan I, Ersoz N, Onguru O, Ozturk M, Kurt B, Cetiner S. Fascin expression in colorectal carcinomas. Clinics. 2010;65(2):157-64.

22. Jung A, Schrauder M, Oswald U, Knoll C, Sellberg P, Palmqvist R, Niedobitek G, Brabletz T, Kirchner T: The invasion front of human colorectal adenocarcinoma shows co-localization of nuclear beta-catenin, cyclin D1, and p16INK4A and is a region of low proliferation. Am J Pathol.2001, 159: 1613-1617.

23. Xie JJ ., XuLyZhang HH, Cai WJ, Mai RQ, Xie YM, Yang ZM, Niu YD, Shen ZY, Li EM: Role of fascin in the proliferation and invasiveness of esophageal carcinoma cells. BiochemBiophys Res Commun. 2005, 337: 355-362

24. MinnAJ ,GuptaGP,, Siegel PM, Bos PD, Shu W, Giri DD, Viale A, Olshen AB, Gerald WL, Massague J: Genes that mediate breast cancer metastasis to lung. Nature.2005, 436: 518-524.

25. Wong NA, Pignatelli M. $\beta$-catenin—a linchpin in colorectal carcinogenesis? Am J Pathol 2002;160:389401.

26. Chung GG, Provost E, Kielhorn EP, Charette LA, Smith BL, Rimm DL. Tissue microarray analysis of betacatenin in colorectal cancer shows nuclear phospho-beta-catenin is associated with a better prognosis. Clin Cancer Res. 2001;7(12):4013-20.

27. Wong SC, Lo ES, Lee KC, Chan JK, Hsiao WL.Prognostic and diagnostic significance of beta-catenin nuclear immunostaining in colorectal cancer. Clin Cancer Res. 2004;10:1401-1408.

28. Martensson A, Oberg A, Jung A, Cederquist K, Stenling R, Palmqvist R. Beta-catenin expression in relation to genetic instability and prognosis in colorectal cancer. Oncol Rep. 2007;17(2):447-52.

29. Mikami T, Mitomi H, Hara A, Yanagisawa N, Yoshida T, Tsuruta O, Okayasu I. Decreased expression of CD44, alpha-catenin, and deleted colon carcinoma and altered expression of beta-catenin in ulcerative colitis-associated dysplasia and carcinoma, as compared with sporadic colon neoplasms. Cancer. 2000;89:733-740.

30. Horkko TT, Klintrup K, Makinen JM, Napankangas JB, Tuominen HJ, Makela J, Karttunen TJ, Makinen MJ. Budding invasive margin and prognosis in colorectal cancer--no direct association with beta-catenin expression. Eur J Cancer. 2006;42:964-971.

31. Roca F, Mauro LV, Morandi A, Bonadeo F, Vaccaro C, Quintana GO, Specterman S, de Kier Joffe EB, Pallotta MG, Puricelli LI, et al. Prognostic value of E-cadherin, beta-catenin, MMPs (7 and 9), and TIMPs (1 and 2) in patients with colorectal carcinoma. J SurgOncol. 2006;93:151-160.

32. StanczakA, StecR , Lubomir B, Wojciech OlszewskiMarzena CichowiczWojciech Kozlowski et al.,Prognostic significance of Wnt-1, $\beta$-catenin and E-cadherin Expression in Advanced Colorectal Carcinoma.Pathol. Oncol. Res. 2011; 17, 4 955-963.

33. Cohan CS, Welnhofer EA, Zhao L, Matsumura F, Yamashiro S. Role of the actin bundling protein fascin in growth cone morphogenesis: localization in filopodia and lamellipodia.Cell Motil Cytoskeleton.2001; 48: 109-20.

34. Ross R, Sudowe S, Beisner J, et al. Transcriptional targeting of dendritic cells for gene therapy using the promoter of the cytoskeletal protein fascin. Gene Ther2003; 10: 1035-40. 